\title{
Levantamento quantitativo e caracterização dendrológica de árvores no campus Tapajós da Universidade Federal do Oeste do Pará
}

O estudo objetivou avaliar o componente arbóreo em áreas de convívio comum no campus Tapajós da UFOPA, através da caracterização dendrológica dos indivíduos. Foram selecionadas as árvores com DAP (diâmetro a altura do peito) igual ou maior a $10 \mathrm{~cm}$ que foram demarcadas com plaquetas numeradas identificadas in loco e em casos em que a identificação não foi possível coletou-se material botânico para consulta à literatura. Foram calculadas as frequências absolutas e relativas. Foram levantados 852 indivíduos distribuídos em 31 famílias botânicas, 62 gêneros e 76 espécies. A família Fabaceae com a maior abundância de espécies (21), a família Anacardiaceae maior abundância de indivíduos (147) e o Protium heptaphyllum foi a espécie mais abundante (103). Os caracteres dendrológicos mais ocorrentes foram fuste inclinado (42), forma circular (64), base reta (51), ritidoma rijo (59) de cor cinza (30) e aparência escamosa (13). Casca interna de cor laranja escuro (19), com odor (57), sem oxidação (49) e sem exsudatos (48). Alburno amarelo intenso (25). Folhas simples (36), filotaxia alterna espiralada (40), consistência cartácea (33), sem odor (47) e presença de apêndices e outros elementos (49). Concluiu-se que há riqueza de espécies no campus, porém a concentração de indivíduos em poucas espécies denota baixa heterogeneidade à vegetação.

\section{Quantitative raising and dendrological description at tapajós campus of Universidade Federal do Oeste do Pará, Santarém}

\begin{abstract}
The objective of this study was to evaluate the arboreal component in common living areas on the Tapajós campus of UFOPA, through the dendrological characterization of the individuals. Trees with DCH (Diameter at Chest Height) equal to or greater than $10 \mathrm{~cm}$ were selected that were demarcated with numbered platelets, identified in loco and in cases where identification was not possible, botanical material was collected for literature consultation. The absolute and relative frequencies were calculated. 852 individuals were raised distributed in 31 botanic families, 62 genders and 75 species. The Anacardiaceae family presented larger individuals' abundance (147) and Fabaceae family presented larger species abundance (21). The Protium heptaphyllum was the most abundant species (103). The dendrological characters more frequent were inclined shaft (42), round shaped (64), straight base, hard rhytidome (59) gray color (30) flaky aspect (13). Dark orange internal bark (19), having odor (57), without oxidation (49) and without exudates (48). Intenside yellow alburnum (35). Simple leaves (36), spiral alternating phyllotaxis (40), chartaceous cohesion. It was concluded that there is a species wealth in the campus but the concentration of individuals in a few species which denotes low heterogeneity to vegetation.
\end{abstract}

Keywords: Dendrology; Campi College Students; Relative frequency; Invading potential.

Topic: Planejamento, Gestão e Políticas Públicas Ambientais

Reviewed anonymously in the process of blind peer.
Received: 02/12/2018

Approved: 26/01/2019
Andressa Jaqueline Viana de Souza

Universidade Federal do Oeste do Pará, Brasi

http://lattes.cnpq.br/1941608083658085

andressa-viana8@hotmail.com

Cristina Aledi Felsemburgh (iD

Universidade Federal do Oeste do Pará, Brasil

http://lattes.cnpq.br/8446110971099607

http://orcid.org/0000-0002-8199-8639

crisalefel@gmail.com

Vanessa Leão Peleja (iD

Universidade Federal do Oeste do Pará, Brasil

http://lattes.cnpq.br/4847354203016902

http://orcid.org/0000-0003-2138-3277

peleja.floresta@gmail.com

\author{
Samuel Alves de Souza (D) \\ Universidade Federal do Oeste do Pará, Brasil \\ http://lattes.cnpq.br/6722755854215175 \\ http://orcid.org/0000-0002-3581-902X \\ sasouza32@gmail.com
}

Referencing this:

SOUZA, A. J. V.; FELSEMBURGH, C. A.; PELEJA, V. L.; SOUZA, S. A.. Levantamento quantitativo e caracterização dendrológica de árvores no campus Tapajós da Universidade Federal do Oeste do Pará. Revista Ibero Americana de Ciências Ambientais, v.10, n.1, p.297-313, 2019. DOI: http://doi.org/10.6008/CBPC2179-6858.2019.001.0025

DOI: 10.6008/CBPC2179-6858.2019.001.0025 


\section{INTRODUÇÃO}

O conhecimento aprofundado dos fragmentos florestais presentes em campi universitários é importante, uma vez que essas áreas verdes atuam como ferramenta didática eficiente em diversos cursos de graduação (OLIVEIRA et al., 2009; COSTA, 2011; SOUZA, 2014) são fonte de pesquisas em várias áreas de estudo além de possibilitar a prática esportiva (BRIANEZI et al., 2013); despertam na comunidade acadêmica e população do entorno, necessidade de manutenção e preservação ambiental através do convívio diário e conhecimento das espécies situadas nesses locais (MELO et al., 2007; OLIVEIRA et al., 2009; BRIANEZI et al., 2013); além de gerar informações sobre a origem dos indivíduos arbóreos (se nativas ou exóticas) (OLIVEIRA, et al., 2009).

De modo geral, a arborização tem importância para o planejamento urbanístico, contribui para a manutenção da biodiversidade e é um elemento estético da paisagem. As instituições de ensino superior e institutos tecnológicos são espaços favoráveis para realização de projetos florísticos, proporcionando um vasto material didático e de pesquisa na área de botânica, como é possível observar na literatura a gama de trabalhos e pesquisas realizadas em campi universitários e institutos federais, como o executado por Melo et al. (2007) no Campus I da Universidade de Passo Fundo, com o intuito de:

[...] conhecer, identificar, localizar, catalogar, conservar e divulgar o valor da preservação da vegetação desta área, bem como proporcionar à comunidade a sensibilização quanto à flora, ao meio ambiente e à melhoria da qualidade de vida, aliada à responsabilidade social da Universidade. (MELO et al., 2007)

Oliveira et al. (2009) realizou um inventário da arborização existente no campus Pato Branco da Universidade Tecnológica Federal do Paraná (UTFPR), com o objetivo principal de conhecer a comunidade vegetal daquele ambiente, uma vez que, segundo o autor, desde a criação do campus, nunca antes havia sido feito um estudo a respeito da arborização situada no mesmo.

Outro importante trabalho foi o realizado no campus-sede da Universidade Federal de Viçosa, inserido no município de Viçosa, Minas Gerais, por Brianezi et al. (2013), com o intuito de avaliar a arborização do campus, identificando as árvores presentes nas vias de acesso, estacionamentos e arboretos estabelecidos ali, avaliando suas condições fitossanitárias, e gerando dados sobre a frequência de indivíduos, contribuído para o conhecimento quali-quantitativo da arborização do local.

A compreensão da diversidade florística dos campi das Instituições de Ensino Superior (IES) é fundamental para a manutenção, manejo e planos diretores, para a caracterização a identidade da instituição e ainda para o fornecimento de informações que possam contribuir para construção de uma sociedade voltada para o desenvolvimento sustentável.

O conhecimento do componente arbóreo para a gestão ambiental torna-se imprescindível às IES que pretendem realizar a implantação e/ou a ampliação de seus campi, permitindo tanto o controle dos impactos ambientais quanto à adequação à legislação ambiental vigente, ainda no momento da elaboração do seu plano diretor e consequentemente na estruturação e na ampliação de sua infraestrutura.

A Universidade Federal do Oeste do Pará conta com três unidades situadas na cidade de Santarém, os Campi: Rondon, Amazônia e Tapajós. Desde a criação da Universidade, o campus Tapajós passou por 
diversas obras de ampliação necessárias para comportar o crescimento da comunidade acadêmica, porém, tal expansão física acabou por alterar a fisionomia do espaço, uma vez que o campus está inserido em área composta por fragmentos florestais. Muitas árvores que estavam situadas nas áreas onde foram executadas as obras foram retiradas sem a realização do inventário completo da composição vegetal e sem avaliação da possibilidade de existência de espécies raras e talvez endêmicas, a função que cada indivíduo poderia prestar dentro do ambiente em que estava inserido, além de não ter sido observado se as espécies suprimidas têm corte autorizado por lei.

Com base no exposto o presente trabalho teve como objetivo principal avaliar o componente arbóreo das áreas de convívio comum inseridas no campus Tapajós da Universidade Federal do Oeste do Pará, através da caracterização dendrológica dos indivíduos arbóreos visando contribuir com informações que servirão de subsídios ao planejamento, gestão dos espaços públicos e para a elaboração do plano diretor da universidade.

\section{MATERIAIS E MÉTODOS}

\section{Descrição da área de estudo}

A Universidade Federal do Oeste do Pará está situada na região do Baixo Amazonas, Oeste do estado do Pará, no município de Santarém. De acordo com a classificação de Köppen o tipo climático da região é Ami (clima tropical chuvoso), apresentando uma estação seca, que se estende de agosto a novembro e uma estação chuvosa, entre os meses de dezembro a junho. Segundo dados do INMET (2018), no ano de 2017 a região apresentou precipitação média anual de $127,5 \mathrm{~mm} / \mathrm{mês}^{-1}$, com média anual de temperatura máxima igual a $31^{\circ} \mathrm{C}$, média anual de temperatura mínima de $22^{\circ} \mathrm{C}$ e umidade relativa de $88 \%$.

A área em que o campus Tapajós está inserido é constituída por diversos fragmentos florestais em estágio inicial de sucessão e sua extensão é de $103.000 \mathrm{~m}^{2}$. O levantamento quantitativo e a demarcação das árvores foram realizados no período de Outubro de 2016 a Janeiro de 2017 e a caracterização dendrológica de Agosto de 2017 a Fevereiro de 2018, em áreas de convívio comum, próximo às salas de aula, laboratórios, coordenações de institutos, onde são realizadas aulas práticas dos mais diversos cursos, ou seja, espaços onde há maior circulação de pessoas e contato dessas com a comunidade vegetal inserida no campus Tapajós.

\section{Demarcação das árvores e coleta botânica}

Foram caracterizadas todas as árvores inseridas dentro da área de estudo que apresentaram DAP (diâmetro a altura do peito a 1,30 m do solo) igual ou maior a $10 \mathrm{~cm}$, tal medida foi aferida com fita diamétrica, e posteriormente os indivíduos foram numerados. As identificações foram realizadas in loco e quando necessário foi realizada a coleta de material botânico com auxílio de podão e escalada das árvores cuja copa estava fora de alcance. A coleta e preparação do material botânico seguiu a metodologia descrita por Silva et al. (2014). 
A identificação taxonômica dos indivíduos não identificados in loco e dos quais não foi possível a coleta de material reprodutivo foi realizada por comparação do material botânico coletado com o depositado no Herbário da Universidade Federal do Oeste do Pará, além de consultas aos Herbários Virtuais do Reflora e do Jabot - Jardim Botânico do Rio de Janeiro e as obras "Árvores Brasileiras: Manual de Identificação e Cultivo de Plantas Arbóreas Nativas do Brasil - Volume 1, 2a Edição" publicado por Lorenzi (2001), “Árvores da Amazônia" de Silva (2006), o "Guia llustrado e Manual de Arquitetura Foliar para Espécies Madeireiras da Amazônia Ocidental" de Obermüller et al. (2011), além de "Flora da Reserva Ducke: Guia de identificação das plantas vasculares de uma floresta de terra-firme na Amazônia Central” de Ribeiro et al. (1999). A classificação foi realizada de acordo com a Angiosperm Phylogeny Group - APG III (2009).

A origem dos indivíduos foi definida de acordo com pesquisa realizada em literaturas científicas e seu potencial invasor, em casos de espécies exóticas, definido de acordo com algumas premissas avaliadas pela Base de Dados Nacional de Espécies Exóticas Invasoras - I3N Brasil, como a capacidade de dominância, hospedagem de parasitas ou patógenos, impacto na economia e impacto na saúde humana. A consulta das espécies em relação à possibilidade de ameaça de extinção foi realizada na Lista vermelha do Centro Nacional de Conservação da Flora - CNCFlora, responsável por avaliar o risco de extinção de espécies da flora do Brasil até 2020.

\section{Levantamento quantitativo}

Como complemento a caracterização dendrológica e através do processamento dos dados coletados com auxílio do programa Microsoft Excel $2010^{\circledR}$, foram calculadas as frequências absoluta e relativa, de acordo com Brianezi et al. (2013).

\section{Caracterização dendrológica}

O processo de caracterização macromorfológica foi realizado com o auxílio de ficha dendrológica, baseada em materiais produzidos por Ribeiro et al. (1999), Lorenzi (2001), Gonçalves et al. (2007), Obermüller et al. (2011), Silva et al. (2014), Miller (2015), e com adaptações.

Os caracteres dendrológicos avaliados nesse estudo foram: Fuste - Avaliações quanto à posição do fuste em relação ao solo, a forma e a base; Ritidoma - Foi caracterizado quanto à resistência, cor e aparência; Casca viva/interna - Foi avaliada a cor, incidência de odores, ocorrência de oxidação, presença e tipo de exsudato; Alburno - O alburno foi avaliado quanto à coloração ao corte; Folhas - Foram avaliadas de acordo com sua composição, filotaxia, consistência, coloração, incidência de odores, ocorrência de apêndices e outros elementos.

\section{RESULTADOS}

\section{Levantamento quantitativo}

Com a realização do estudo foram avaliados um total de 852 indivíduos arbóreos, distribuídos em 31 famílias botânicas, 62 gêneros e 76 espécies, sendo que 5 indivíduos foram identificados apenas a nível de 
gênero e 2 indivíduos apenas a nível de família botânica. Todos os espécimes avaliados no estudo pertencem à classe das angiospermas.

De 31 famílias, apenas 5 concentram boa parte dos indivíduos ocorrentes na área de estudo, dentre elas está a Anacardiaceae (17,3\%) com 147 indivíduos, Fabaceae (15\%) com 128 indivíduos distribuídos entre as subfamílias Papilionaceae (47), Caesalpiniaceae (41) e Mimosaceae (40). Burseraceae em terceiro (12,1\%) com 103 indivíduos, seguida por Bignoniaceae (10,2\%) com 87 indivíduos e pela família Myrtaceae (7\%) apresentando 60 indivíduos. Um total de 5 famílias apresentaram valores entre 1,5 e 1,2\% e outras 10 famílias apresentaram valores inferiores a $1 \%$.

Em relação à origem das espécies encontradas no campus apenas 5 são exóticas, e estão distribuídas em 4 famílias botânicas (Tabela 1). A espécie exótica com maior número de indivíduos (13) na área de estudo foi a Mangifera indica L. (mangueira), pertencente à família Anacardiaceae cuja origem é do Sul da Ásia (SILVA et al., 2007).

A Leucaena leucocephala (Lam.) de Wit (leucena), da família Fabaceae subfamília Mimosaceae, originária da América Central (COSTA et al., 2010) e o Psidium guajava L. (goiabeira), da família Myrtaceae cuja origem é incerta, podendo ser do México ou do Norte da América do Sul (SILVA et al., 2007), também ocorreram no campus Tapajós, com 4 indivíduos cada.

A quarta espécie exótica encontrada no campus Tapajós foi a Syzygium malaccense (L.) Merr. \& Perry. (jambeiro) de origem asiática (India e Malásia) (COSTA et al., 2006) e pertencente à família Myrtaceae, apresentou 2 indivíduos, além da espécie Ficus benjamina L., família Moraceae, de origem indiana (SILVA et al., 2007), representada por 1 indivíduo.

Tabela 1: Família, nome científico, nome vulgar, número total de indivíduos e origem das espécies (nativa ou exótica) encontradas na área de estudo.

\begin{tabular}{|c|c|c|c|c|}
\hline Família & Nome científico & Nome vulgar & $\begin{array}{l}\text { № de de } \\
\text { indivíduos }\end{array}$ & Origem \\
\hline \multirow[t]{5}{*}{ ANACARDIACEAE } & Anacardium occidentale L. & Cajueiro & 16 & Nativa \\
\hline & Mangifera indica $\mathrm{L}$. & Mangueira & 13 & Exótica \\
\hline & Myracrodruon urundeuva Allemão. & Aroeira-do-sertão & 16 & Nativa \\
\hline & Spondias mombin $\mathrm{L}$. & Taperebazeiro & 15 & Nativa \\
\hline & Tapirira guianensis Aubl. & Tatapiririca & 87 & Nativa \\
\hline \multirow[t]{3}{*}{ ANONNACEAE } & Rollinia bahiensis Maas \& Westra & Envira-preta & 6 & Nativa \\
\hline & Xylopia amazonica R.E.Fr. & Envira-x & 10 & Nativa \\
\hline & Xylopia aromatica Lam. (Mart) & Envira-branca & 2 & Nativa \\
\hline APOCYNACEAE & Aspidosperma carapanauba Pichon. & Araracanga & 4 & Nativa \\
\hline \multirow[t]{3}{*}{ BIGNONIACEAE } & Handroanthus impetiginosus Mattos & Ipê-roxo & 1 & Nativa \\
\hline & Handroanthus sp. & Ipê-da-praia & 11 & Nativa \\
\hline & Handroanthus serratifolius (Vahl) S.Grose. & Ipê-amarelo & 75 & Nativa \\
\hline BORAGINACEAE & Cordia goeldiana Huber & Freijó-branco & 13 & Nativa \\
\hline BURSERACEAE & $\begin{array}{l}\text { Protium heptaphyllum (Aubl.) Marchand } \\
\text { subsp. Heptaphyllum }\end{array}$ & Breu-branco & 103 & Nativa \\
\hline CARYOCARACEAE & Caryocar villosum (Aubl.) Pers. & Piquazeiro & 1 & Nativa \\
\hline \multirow[t]{2}{*}{ CHRYSOBALANACEAE } & Não identificada & Capitíu & 9 & N.I \\
\hline & Couepia sp & Axixá & 9 & Nativa \\
\hline CLUSIACEAE & Garcinia mangostana $\mathrm{L}$. & Mangostão & 2 & Nativa \\
\hline COMBRETACEAE & Buchenavia grandis Ducke. & Cuiarana-de-caroço & 3 & Nativa \\
\hline CONNARACEAE & Connarus sp. & Cunário & 2 & Nativa \\
\hline DILLENIACEAE & Curatella americana $\mathrm{L}$. & Cipó-de-fogo & 1 & Nativa \\
\hline EUPHORBIACEAE & Sapium glandulatum (Vell.) Pax. & Burra-leiteira & 6 & Nativa \\
\hline FABACEAE - CAELSAPINIACEAE & Bauhinia forficata Link. & Pata-de-vaca & 4 & Nativa \\
\hline
\end{tabular}




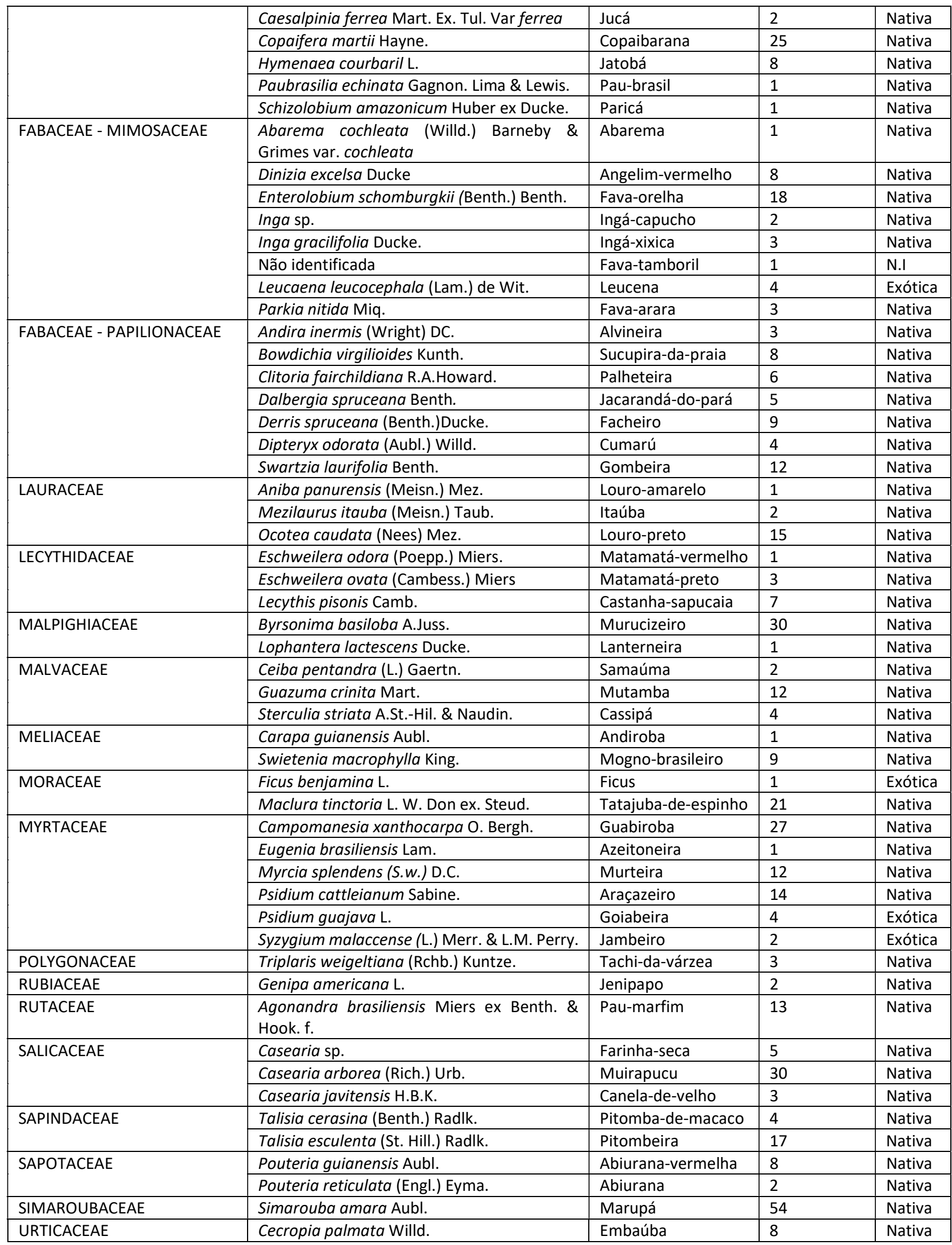

N.I - Não identificada.

Em consulta ao banco de dados da I3N Brasil foi possível observar que 4 das 5 espécies exóticas ocorrentes no campus Tapajós da UFOPA apresentam potencial invasor, sendo elas a $M$. indica, L. leucocephala, P. guajava e S. malaccense. Ao analisar alguns caracteres propostos pelo I3N Brasil, como a capacidade de estabelecimento e dominância das espécies, tendência a hospedar parasitas ou patógenos, 
impactos na economia e na saúde humana, a fim de definir o potencial invasor de espécies exóticas no Brasil, foi possível definir que $M$. indica e $P$. guajava possuem alta adaptabilidade, no entanto $M$. indica, tem baixa capacidade de dominância, não tendo facilidade de formar núcleos densos, assim como S. malaccense enquanto $P$. guajava $L$. tem por característica suprimir a flora nativa em estágios iniciais de sucessão e $L$. leucocephala tem tendência a formar núcleos de alta densidade. Em relação à presença de hospedeiros parasitas ou patógenos apenas $L$. leucocephala apresenta possibilidade de ocorrência, segundo verificado no banco de dados do I3N Brasil.

Quanto a impactos na economia apenas $P$. guajava apresentou algum potencial de geração de custos em casos em que sua remoção se faz necessária, como em áreas destinadas à pastagem ou agricultura, o que não condiz com a realidade da área de estudo. No que diz respeito à saúde humana as 4 espécies exóticas com potencial invasor ocorrentes no campus Tapajós da UFOPA apresentam impacto baixo ou nulo. A espécie exótica F. benjamina apesar de não ser frutífera, não apresenta potencial invasor reconhecido pelo I3N Brasil.

De acordo com a Lista vermelha do CNCFlora (2012) duas espécies encontradas no campus Tapajós se enquadram na categoria 'vulnerável', ou seja, são espécies que enfrentam um risco elevado na natureza, sendo estas a Mezilaurus itauba (Meisn.) Taub. ex Mez (itaúba) e a Swietenia macrophylla King. (mognobrasileiro). A espécie Paubrasilia echinata Gagnon, Lima \& Lewis está incluída na categoria 'em perigo', ou seja, espécie que apresenta um nível muito elevado de extinção na natureza.

Em relação aos cálculos das frequências absolutas ( $F A$ ) e frequências relativas ( $F R$ ) para todos os indivíduos avaliados no estudo, a espécie Protium heptaphyllum (Aubl.) Marchand subsp. heptaphyllum (breu-branco), da família Burseraceae teve destaque, pois apresenta 103 indivíduos (FA) e de 12,18\% da representatividade vegetal na área de estudo (FR) (Tabela 2).

Avaliando as famílias de modo individual com a finalidade de verificar a riqueza de espécies inseridas na área, em primeiro lugar está a família Fabaceae, que apresentou uma maior quantidade de espécies no campus (21), estando essas espécies distribuídas nas subfamílias Mimosaceae (8), Papilionaceae (7) e Caesalpiniaceae (6). A Família Myrtaceae ocupou a segunda posição na diversidade de espécies (6) seguida por Anacardiaceae (5).

Tabela 2: Nome científico, nome comum, família botânica, frequência absoluta, frequência relativa, e DAP médio das espécies encontradas na área de estudo.

\begin{tabular}{|c|c|c|c|c|c|}
\hline Nome científico & Nome comum & Família botânica & FA & $\begin{array}{l}\text { FR } \\
(\%)\end{array}$ & $\begin{array}{l}\text { DAP } \\
\text { médio } \\
(\mathrm{m})\end{array}$ \\
\hline $\begin{array}{l}\text { Protium heptaphyllum (Aubl.) Marchand subsp. } \\
\text { Heptaphyllum }\end{array}$ & Breu-branco & Burseraceae & 103 & 12,06 & 0,92 \\
\hline Tapirira guianensis Aubl. & Tatapiririca & Anacardiaceae & 87 & 10,19 & 0,51 \\
\hline Handroanthus serratifolius (Vahl) S.Grose & Ipê-amarelo & Bignoniaceae & 75 & 8,78 & 0,74 \\
\hline Simarouba amara Aubl. & Marupá & Simaroubaceae & 54 & 6,32 & 0,60 \\
\hline Casearia arborea (Rich.) Urb. & Muirapucu & Salicaceae & 30 & 3,51 & 0,28 \\
\hline Birsonima basiloba A. Juss. & Murucizeiro & Malpighiaceae & 30 & 3,51 & 0,38 \\
\hline Campomanesia xanthocarpa O. Bergh. & Guabiroba & Myrtaceae & 27 & 3,16 & 0,64 \\
\hline Copaifera martii Hayne. & Copaibarana & Fabaceae - Caesalpiniaceae & 25 & 2,93 & 0,95 \\
\hline Maclura tinctoria L. W. Don ex. Steud. & Tatajuba-de-espinho & Moraceae & 21 & 2,46 & 0,44 \\
\hline Enterolobium schomburgkii Benth. & Fava-orelha & Fabaceae - Mimosaceae & 18 & 2,11 & 0,95 \\
\hline Talisia esculenta (St. Hill.) Radlk. & Pitombeira & Sapindaceae & 17 & 1,99 & 0,75 \\
\hline Myracrodruon urundeuva Allemão. & Aroeira-do-sertão & Anacardiaceae & 16 & 1,87 & 0,67 \\
\hline
\end{tabular}




\begin{tabular}{|c|c|c|c|c|c|}
\hline Anacardium occidentale L. & Cajueiro & Anacardiaceae & 16 & 1,87 & 0,85 \\
\hline Ocotea caudata (Nees) Mez. & Louro-preto & Lauraceae & 15 & 1,76 & 1,20 \\
\hline Spondias mombin L. & Taperebazeiro & Anacardiaceae & 15 & 1,76 & 0,94 \\
\hline Psidium cattleianum Sabine. & Araçazeiro & Myrtaceae & 14 & 1,64 & 0,45 \\
\hline Cordia goeldiana Huber. & Freijó-branco & Boraginaceae & 13 & 1,52 & 0,31 \\
\hline Mangifera indica $\mathrm{L}$. & Mangueira & Anacardiaceae & 13 & 1,52 & 1,26 \\
\hline $\begin{array}{l}\text { Agonandra brasiliensis Miers ex Benth. \& Hook. } \\
\text { f. }\end{array}$ & Pau-marfim & Rutaceae & 13 & 1,52 & 0,41 \\
\hline Swartzia laurifolia Benth. & Gombeira & Fabaceae - Papilionaceae & 12 & 1,41 & 0,71 \\
\hline Myrcia splendens (S.w.) D.C. & Murteira & Myrtaceae & 12 & 1,41 & 0,54 \\
\hline Guazuma crinita Mart. & Mutamba & Malvaceae & 12 & 1,41 & 0,47 \\
\hline Handroanthus sp & Ipê-da-praia & Bignoniaceae & 11 & 1,29 & 0,98 \\
\hline Xylopia amazonicaR.E.Fr. & Envira-x & Annonaceae & 10 & 1,17 & 0,40 \\
\hline Couepia sp & Axixá & Chrysobalanaceae & 9 & 1,05 & 0,83 \\
\hline Não identificada & Capitiú & Chrysobalanaceae & 9 & 1,05 & 0,56 \\
\hline Derris spruceana (Benth.) Ducke. & Facheiro & Fabaceae - Papilionaceae & 9 & 1,05 & 0,46 \\
\hline Swietenia macrophylla King & Mogno-brasileiro & Meliaceae & 9 & 1,05 & 0,53 \\
\hline Pouteria guianensis Aubl. & Abiurana vermelha & Sapotaceae & 8 & 0,94 & 1,27 \\
\hline Dinizia excelsa Ducke. & Angelim-vermelho & Fabaceae - Mimosaceae & 8 & 0,94 & 0,45 \\
\hline Cecropya palmata Willd. & Embaúba & Urticaceae & 8 & 0,94 & 0,55 \\
\hline Hymenaea courbaril L. & Jatobá & Fabaceae - Caesalpiniaceae & 8 & 0,94 & 1,57 \\
\hline Bowdichia virgilioides Kunth. & Sucupira-da-praia & Fabaceae - Papilionaceae & 8 & 0,94 & 0,86 \\
\hline Lecythis pisonis Camb. & Castanha-sapucaia & Lecythidaceae & 7 & 0,82 & 0,80 \\
\hline Sapium glandulatum (Vell.) Pax. & Burra-leiteira & Euphorbiaceae & 6 & 0,70 & 0,59 \\
\hline Rollinia bahiensis Maas \& Westra. & Envira-preta & Annonaceae & 6 & 0,70 & 0,55 \\
\hline Clitoria fairchildiana R. A. Howard. & Palheteira & Fabaceae - Papilionaceae & 6 & 0,70 & 0,71 \\
\hline Casearia $\mathrm{sp}$ & Farinha-seca & Salicaceae & 5 & 0,59 & 0,36 \\
\hline Dalbergia spruceana Benth. & Jacarandá-do-Pará & Fabaceae - Papilionaceae & 5 & 0,59 & 0,53 \\
\hline Aspidosperma carapanauba Pichon. & Araracanga & Apocynaceae & 4 & 0,47 & 1,02 \\
\hline Sterculia striata A.St.-Hil. \& Naudin. & Cassipá & Malvaceae & 4 & 0,47 & 0,83 \\
\hline Dipteryx odorata (Aubl.) Willd. & Cumarú & Fabaceae - Papilionaceae & 4 & 0,47 & 0,50 \\
\hline Xylopia aromatica Lam. (Mart) & Envira-branca & Annonaceae & 4 & 0,47 & 0,51 \\
\hline Psidium guajava $\mathrm{L}$. & Goiabeira & Myrtaceae & 4 & 0,47 & 0,42 \\
\hline Leucaena leucocephala (Lam.) de Wit. & Leucena & Fabaceae - Mimosaceae & 4 & 0,47 & 0,41 \\
\hline Bauhinia forficata Link. & Pata-de-vaca & Fabaceae - Caesalpiniaceae & 4 & 0,47 & 0,52 \\
\hline Talisia cerasina (Benth.) Radlk & Pitomba-de-macaco & Sapindaceae & 4 & 0,47 & 0,16 \\
\hline Andira inermis (Wright) DC. & Alvineira & Fabaceae - Papilionaceae & 3 & 0,35 & 1,49 \\
\hline Casearia javitensis H.B.K. & Canela-de-velho & Salicaceae & 3 & 0,35 & 0,21 \\
\hline Buchenavia grandis Ducke. & Cuiarana-de-caroço & Combretaceae & 3 & 0,35 & 0,73 \\
\hline Parkia nitida Miq. & Fava-arara & Fabaceae - Mimosaceae & 3 & 0,35 & 1,84 \\
\hline Inga gracilifolia Ducke. & Ingá-xixica & Fabaceae - Mimosaceae & 3 & 0,35 & 0,47 \\
\hline Eschweilera ovata (Cambess.) Miers. & Matamata-preto & Lecythidaceae & 3 & 0,35 & 0,85 \\
\hline Triplaris weigeltiana (Rchb.) Kuntze. & Tachi-da-várzea & Polygonaceae & 3 & 0,35 & 0,84 \\
\hline Pouteria reticulata (Engl.) Eyma. & Abiurana & Sapotaceae & 2 & 0,23 & 0,58 \\
\hline Connarus sp & Cunário & Connaraceae & 2 & 0,23 & 0,57 \\
\hline Inga sp & Ingá-capucho & Fabaceae - Mimosaceae & 2 & 0,23 & 0,97 \\
\hline Mezilaurus itauba (Meisn.) Taub. & Itaúba & Lauraceae & 2 & 0,23 & 0,97 \\
\hline Eugenia malaccensis $\mathrm{L}$. & Jambeiro & Myrtaceae & 2 & 0,23 & 1,69 \\
\hline Genipa americana $\mathrm{L}$. & Jenipapo & Rubiaceae & 2 & 0,23 & 0,69 \\
\hline Caesalpinia ferrea Mart. Ex. Tul. Var ferrea & Jucá & Fabaceae - Caesalpiniaceae & 2 & 0,23 & 0,77 \\
\hline Garcinia mangostana $\mathrm{L}$. & Mangostão & Clusiaceae & 2 & 0,23 & 0,84 \\
\hline Ceiba pentandra Gaertn. & Samaúma & Malvaceae & 2 & 0,23 & 1,93 \\
\hline $\begin{array}{l}\text { Abarema cochleata (Willd.) Barneby \& Grimes } \\
\text { var. cochleata }\end{array}$ & Abarema & Fabaceae - Mimosaceae & 1 & 0,12 & 0,33 \\
\hline Carapa guianensis Aubl. & Andiroba & Meliaceae & 1 & 0,12 & 0,53 \\
\hline Eugenia brasiliensis Lam. & Azeitoneira & Myrtaceae & 1 & 0,12 & 0,75 \\
\hline Curatella americana $\mathrm{L}$. & Cipó-de-fogo & Dilleniaceae & 1 & 0,12 & 1,14 \\
\hline Não identificada & Fava-tamboril & Fabaceae - Mimosaceae & 1 & 0,12 & 1,21 \\
\hline Ficus benjamina $\mathrm{L}$. & Ficus & Moraceae & 1 & 0,12 & 1,24 \\
\hline Handroanthus impetiginosus Mattos. & Ipê-roxo & Bignoniaceae & 1 & 0,12 & 1,78 \\
\hline Lophantera lactescens Ducke. & Lanterneira & Malpighiaceae & 1 & 0,12 & 0,20 \\
\hline Aniba panurenis (Meisn.) Mez. & Louro-amarelo & Lauraceae & 1 & 0,12 & 1,72 \\
\hline Eschweilera odora (Poepp.) Miers. & Matamata-vermelho & Lecythidaceae & 1 & 0,12 & 1,28 \\
\hline Schizolobium amazonicum & Paricá & Fabaceae - Caesalpiniaceae & 1 & 0,12 & 1,97 \\
\hline
\end{tabular}


Paubrasilia echinata Gagnon, Lima \& Lewis. Caryocar villosum (Aubl.) Pers.

Pau-brasil
Piquiazeiro
Fabaceae - Caesalpiniaceae

Caryocaraceae
0,12

0,12

0,18

1,30

\section{Caracterização Dendrológica}

A caracterização dendrológica foi realizada para todas as espécies encontradas no campus, inclusive naquelas as quais não foi possível a identificação em nível de espécie, exceto para a espécie Handroanthus impetiginosus Mattos (ipê-roxo), que apresentou apenas um indivíduo na área de estudo onde, no momento da caracterização in loco não foi possível à aproximação da árvore, pois a mesma oferecia risco por estar infestado por abelhas. Desta forma a espécie Handroanthus impetiginosus Mattos foi caracterizada apenas em relação à dendrologia do fuste (posição, forma e base) e das folhas (composição, filotaxia, consistência, odor e apêndices).

A avaliação da posição do fuste das árvores em relação ao solo mostrou que das 76 espécies avaliadas, 42 apresentaram fuste inclinado e 34 espécies com fuste em posição ereta. Quanto à forma, 64 espécies apresentaram fuste circular e 4 apresentaram formato tortuoso, apresentando sinuosidades no sentido longitudinal, e as 8 espécies restantes se dividiram entre forma acanalada, nodosa e torcida. Já em relação ao formato da base, boa parte das espécies apresentou base reta (51), seguidas pela base do tipo dilatada (10), e as demais (15) se dividiram entre acanalada, digitada e com sapopemas (Figura 1A).

Na caracterização dendrológica do ritidoma foram avaliados os caracteres resistência e cor. Quanto à resistência, 59 espécies apresentaram ritidoma rijo, com alta resistência ao corte ou atrito, o que corresponde a $78 \%$ das espécies avaliadas. A cor cinza teve predominância nos ritidomas avaliados com 34 indivíduos (46\% das espécies), e a cor marrom na segunda posição com 29 indivíduos (39\%) (Figuras 1B).

O ritidoma, também avaliado nesse estudo quanto à aparência, quando observado apresenta grande variação de padrões entre espécies, sendo um caractere importante em uma avaliação dendrológica. No campus Tapajós os ritidomas com aparência escamosa, ou seja, coberto por placas com fendas verticais, podendo ser rígidas e lenhosas, ou finas e esfarelantes, foi maioria nas espécies avaliadas (13), seguido pelo aspecto sujo e áspero (12), ocorrente quando o ritidoma não apresenta um aspecto muito bem definido, podendo apresentar fendas, lenticelas, desprendimento, no entanto, nenhum desses aspectos define de forma majoritária o aspecto do fuste do indivíduo (Figuras 1C). Quanto à coloração da casca interna a que mais se destacou nesse estudo foi a laranja sendo representadas pelas variações laranja-escuro (14) e laranjaclaro (19) (Figura 1D).

Das 75 espécies avaliadas 57 apresentaram algum tipo de odor variando entre os agradáveis até odores fétidos, e 18 espécies não apresentaram odor característico que possa auxiliar em sua identificação no campo (Figura 1E). Ainda em relação à casca interna foram avaliados os caracteres oxidação e a ocorrência de exsudatos. A maioria das espécies (49) e apenas 26 espécies apresentaram algum tipo de mudança após o corte. Quanto à presença de exsudatos 48 espécies não apresentaram nenhum tipo de exsudação e 24 apresentaram exsudações distribuídas dentre os tipos goma, látex, resina e seiva. 
Figura 1: A - Caracterização do fuste quanto à posição em relação ao solo, forma e base; B - Resistência e coloração do ritidoma; C - Aparência do ritidoma; D - Coloração da casca interna; E - Odor, oxidação e presença de exsudato na casca interna; F-Coloração do alburno; G - Composição foliar; H - Filotaxia, consistência, odor e presença de apêndices e outros elementos nas lâminas foliares.
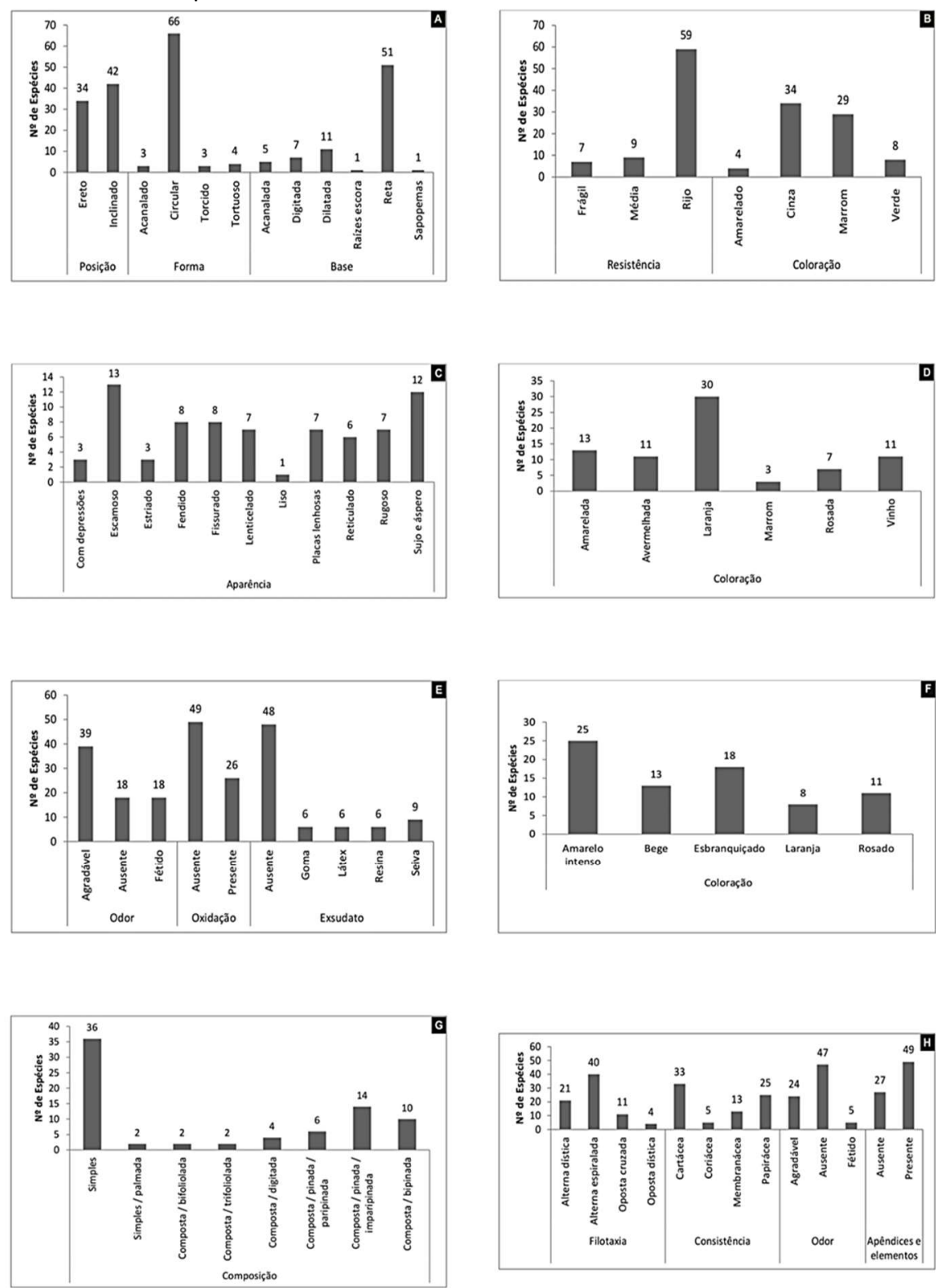

Em relação à caracterização dendrológica do alburno, foi avaliada apenas quanto à coloração. A coloração amarelo intenso obteve maior incidência no campus Tapajós, ocorrendo em 25 alburnos das 75 espécies avaliadas, sendo seguida pela coloração esbranquiçada com 18 e posteriormente a coloração bege (13), a cor laranja foi a menos frequente ocorrendo em apenas 8 espécies (Figura 1F). Inicialmente a caracterização foliar foi feita em relação a sua composição (Figura 1G). Houve maior ocorrência de espécies com composição foliar do tipo simples (36), estando distribuídas nas famílias como Annonaceae, Chrysobalanaceae, Lauraceae, Lecythidaceae, Moraceae e Sapotaceae.

Ainda na caracterização foliar foi avaliada a filotaxia das espécies além da consistência ao tato (caractere bem diverso e passível de interpretação), a presença de odores característicos seja ao natural ou quando a lâmina foliar é macerada, presença de apêndices foliares como estípulas, gemas, lenticelas, glândulas secretoras e outros elementos como galhas causadas por insetos e gemas axilares e apicais 
proeminentes (Figura 1H). Das espécies avaliadas 49 apresentaram algum tipo de apêndice como estípulas intra ou interpeciolares. Ocorreram também estípulas terminais do tipo esporão de galo ou capuz de bruxa. Outros elementos encontrados nesse estudo foram galhas causadas por insetos e gemas axilares e apicais proeminentes.

\section{DISCUSSÃO}

\section{Levantamento quantitativo}

A predominância dos indivíduos pertencentes às famílias Fabaceae, Bignoniaceae e Myrtaceae, que nesse estudo ficaram entre as cinco mais populosas, já foi observada em outros estudos como de Oliveira et al. (2009), Brianezi et al. (2013) e Souza et al. (2014), também realizados em ambientes universitários. Quanto as espécies arbóreas de origem exótica, Paiva (2009) aponta que as mesmas não devem ser excluídas de projetos de arborização urbana, porém ressalta que é importante que a porcentagem do emprego dessas espécies em projetos de arborização seja menor em detrimento das nativas, uma vez que tais projetos objetivam um papel estético e funcional, corroborando com os serviços ambientais e interações entre a fauna e a flora, que muitas vezes não é cumprido pelas espécies exóticas, sem levar em conta o potencial invasor que muitas apresentam.

$\mathrm{Na}$ área de estudo 2,8\% da paisagem arbórea é constituída de árvores de origem exótica, totalizando 24 indivíduos. O resultado observado no campus é diferente, uma vez que na maioria dos estudos realizados em campi universitário e na arborização de vias, praças e parques urbanos (BRIANEZI et al., 2013; LEITE et al., 2014; SOUZA et al., 2014; TEIXEIRA et al., 2016) houve predominância de espécies exóticas em detrimentos de nativas, exceto no estudo realizado por Costa et al. (2011) na Universidade Tecnológica Federal do Paraná (UTFPR) - campus Dois Vizinhos onde de 43 espécies encontradas apenas 5 eram exóticas, e de Oliveira et al. (2009) na Universidade Tecnológica Federal do Paraná (UTFPR) - campus Pato Branco, onde, apesar da pequena margem de diferença (23 nativas e 19 exóticas) houve predominância de espécies nativas.

Apesar de quatro das cinco espécies exóticas encontradas apresentarem potencial invasor de acordo com p I3N Brasil, ao se avaliar alguns aspectos levantados por esta plataforma, tais espécies não apresentam risco ao equilíbrio ecossistêmico da paisagem do campus uma vez que, de modo geral, apresentam baixa capacidade de dominância, não apresentam riscos elevados à saúde da comunidade acadêmica ou riscos de impactos econômicos consideráveis, excetuando-se a espécie L. leucocephala, que como avaliado pelo I3N Brasil, tem tendência a colonizar naturalmente a área onde está situada formando núcleos adensados e podendo suprimir a flora nativa em estágios iniciais de sucessão; movimento esse que já é observado no campus.

É importante ressaltar que além da baixa incidência de espécies e indivíduos de origem exótica na área, três dessas espécies são frutíferas ( $M$. indica, $P$. guajava e $S$. malaccense) podendo ser consideradas atrativas a avifauna e atuar como fonte alternativa em sua alimentação (KERN et al., 2013). A espécie exótica 
F. benjamina apesar de não ser frutífera, não apresenta potencial invasor reconhecido pelo I3N Brasil, no entanto, Barros et al. (2010) ressaltam em seu estudo que essa espécie é conhecida por causar danos estruturais em arborizações urbanas, quebrando calçadas, além de potenciais conflitos com redes de serviço e construções.

Quanto ao risco de extinção das espécies do campus, o CNCFlora (2012) justificativa o enquadramento de $M$. itauba na categoria vulnerável pelo fato dessa espécie ser uma das mais exploradas na região amazônica para a produção de embarcações, levando em conta também a destruição do seu hábitat natural, crescimento lento, tempo de geração de pelo menos 50 anos, além da suspeita de que $M$. itauba tenha sofrido declínio populacional mínimo de 30\% nos últimos 150 anos.

Quanto ao enquadro de S. macrophylla nesta mesma categoria justifica-se por se tratar de uma das espécies atuais com madeira mais valiosa e largamente explorada no Brasil de forma predatória, e sua distribuição atual coincide com as regiões com mais altos índices de desmatamento da Amazônia brasileira, acarretando no declínio de no mínimo 30\% das populações nas ultimas três gerações (CNCFLORA, 2012).

A espécie $P$. echinata, enquadrada na categoria em perigo tem histórico de exploração de mais de 500 anos no país, sendo típica do bioma Mata-atlântica, um dos mais explorados no mundo. Apesar da extração madeireira para produção de corante ter cessado por volta de 1800 o novo mercado de extração para a produção de arcos para violino ganhou notoriedade e tende a aumentar com o incremento da produção industrial em larga escala com a entrada de países como a China no mercado, tornando necessária a criação de unidades de conservação nas áreas de ocorrência, acompanhada de fiscalização, para que a espécie possa ser preservada (CNCFLORA, 2012).

O gênero Protium, a qual pertence a única espécie e a mais populosa na área de estudo ( $P$. heptaphyllum) é normalmente encontrado em vegetação primária e secundária, em terra firme e também em solo arenoso sendo o breu-branco bastante empregado na arborização urbana e rural por fatores como suas qualidades ornamentais e por proporcionar boa sombra (LORENZI, 1998; SILVA, 2006).

A diversidade da família Fabaceae é muito comum em estudos que abordam as áreas verdes urbanas e campi universitários, como demonstrado por Brianezi et al. (2013) em estudo realizado no campus-sede da UFV, onde de 114 espécies encontradas, 31 pertenciam a família Fabaceae (sendo quase 39\% dessas espécies incluídas na subfamília Caesalpiniaceae). O mesmo foi observado por Santos et al. (2017) no diagnóstico de arborização realizado no Parque Tucumã em Rio Branco, Acre, onde de 69 espécies encontradas, 24 pertenciam à família Fabaceae.

É recomendado que a arborização urbana não se constitua em mais de $15 \%$ por árvores de uma mesma espécie de forma a obter uma composição vegetal mais diversificada, um melhor planejamento de arborização além de minimizar a propagação de patogenicidades e atrair fauna mais diversificada (MIRANDA et al., 2009; BRIANEZI et al., 2013; KERN et al., 2013).

$\mathrm{Na}$ área de estudo nenhuma das espécies encontradas obtiveram FR superior a 15\%, uma vez que a espécie com maior número de indivíduos (P. heptaphyllum) apresentou FR de 12,06\%. Leite et al. (2014) e Oliveira et al. (2009) também apresentaram resultados similares em seus estudos. No entanto, ao se analisar 
de forma conjunta, as dez espécies com maior FR (Tabela 2) somadas apresentam representatividade de 55,04\% na área, similar ao resultado obtido por Brianezi et al. (2013), demonstrando que o campus Tapajós possui baixa heterogeneidade, uma vez que há uma concentração da maior parte dos indivíduos em um número reduzido de espécies botânicas.

\section{Caracterização dendrológica}

A caracterização dendrológica de árvores possibilita maior rapidez na diferenciação de espécies similares e identificação de indivíduos em nível de espécie e o agrupamento em famílias, facilitando o processo de identificação botânica além de dar suporte no emprego de espécies em locais adequados de acordo com as características apresentadas pelo indivíduo arbóreo.

No campus a cor cinza predominante na maioria dos ritidomas avaliados também teve ocorrência em levantamento dendrológico realizado por Santos et al. (1998) na bacia do Rio São Bartolomeu, em Viçosa, Minas gerais, todas as espécies avaliadas apresentaram coloração cinza, variando entre cinza claro e cinza escuro.

As fendas e fissuras encontradas em boa parte das espécies do campus são frequentes em espécies florestais, e são ocasionadas por tensões geradas pelo crescimento secundário, o qual exerce força centrífuga sobre os tecidos situados externamente ao câmbio vascular, sendo tal força ocorrente em forma de pressão tangencial sobre o ritidoma, que acaba se rompendo e anulando temporariamente o esforço, uma vez que, por ser um tecido formado por células, não tem capacidade de manter a integridade da casca de forma definitiva (MARCHIORI, 2013).

No levantamento dendrológico realizado por Oliveira et al. (2015) em uma área localizada no ramal da Assurini, cidade de Altamira, Pará, houve predominância de árvores com o aspecto sujo e áspero, de 59 indivíduos avaliados $74 \%$ apresentaram esse tipo de aparência, que também obteve ocorrência expressiva na aparência das espécies no campus Tapajós, pois a diferença numérica desse aspecto de ritidoma para o fissurado (maior ocorrência no campus), foi de apenas uma espécie.

Segundo Silva (2014) a coloração da casca interna é considerada um caráter subjetivo, podendo ser influenciada pela claridade, umidade além da avaliação pessoal de quem faz a caracterização, no entanto, trata-se de um aspecto dendrológico importante e que deve ser considerado sempre que possível. Na área de estudo foi possível observar a variedade existente desse aspecto dendrológico, apresentando tonalidades que podem ser consideradas similares a ponto de serem iguais em avaliação de terceiro, o que reforça a subjetividade desse elemento.

Outro aspecto que também pode ser considerado subjetivo é o odor exalado pela casca interna, porém, é muito importante na identificação de espécies, como no caso de indivíduos da família Lauraceae, cujo gênero Ocotea teve um representante na composição arbórea da área de estudo, a Ocotea caudata (Nees) Mez. (louro-preto), que exala forte cheiro de canela quando cortada, além do $P$. heptaphyllum que apresenta odor mentolado característico, tanto nas folhas quanto ao corte, e que auxilia em sua identificação em campo. 
Dentre as espécies que apresentaram oxidação, ou seja, a exposição ao ar acarretou em alterações significativas no aspecto inicial da casca, podemos citar o $F$. benjamina (ficus) que apresentou mudança mais discreta, passando de uma coloração bege para rosada após exposição, ou na mudança menos sutil ocorrente na espécie Andira inermis (Wright) DC. (alvineira) onde, depois de oxidada, a casca passou de laranja para um marrom bem escurecido.

Quanto à presença de exsudatos, as espécies que apresentaram exsudação do tipo látex são pertencentes às famílias Clusiaceae, Euphorbiaceae, Moraceae e Sapotaceae, cuja presença desse tipo de exsudato é um caractere de diferenciação na identificação de espécies dessas famílias. O mesmo incidiu para as exsudações do tipo resina, que ocorreram nas espécies das famílias, Anacardiaceae e Burseraceae, enquanto as do tipo goma ficaram restritas a espécies da família Fabaceae.

Em relação a caracterização foliar a presença de apêndices foliares como estípulas intra ou interpeciolares são características importantes na identificação de famílias e espécies, como é o caso da Clitoria fairchildiana R. A. Howard (Palheteira), pertencente à família Fabaceae subfamília Papilionaceae cuja característica importante de identificação é a ocorrência de estípulas de base, apresentadas por tal espécie. $\mathrm{Ou}$ as espécies pertencentes à subfamília Mimosaceae encontradas no campus que em sua maioria apresentaram glândulas, característica evidente desta subfamília. Além da característica comum a família Fabaceae, a presença de pulvinos e pulvínulos em caso de folha composta.

Outros apêndices foliares também foram observados como é o caso da presença de estípula terminal do tipo esporão de galo ou capuz de bruxa em indivíduos das espécies Ficus benjamina L. (ficus) e Triplaris weigeltiana (Rchb.) Kuntze. (tachi-da-várzea), além de outros elementos encontrados como a presença de galhas causadas por insetos nas folhas de Simarouba amara Aubl. (marupá) e de Lecythis pisonis Camb. (Castanha-sapucaia), e ainda gemas axilares e apicais proeminentes em Xylopia aromatica Lam. (Mart) (envira-branca) e em Campomanesia xanthocarpa O. Bergh. (guabiroba).

De acordo com Patrício (2017) as IES, ao se levar em conta seu potencial de produção científica, são excelentes espaços para projetos florísticos, porém, tais projetos devem sempre procurar considerar os caracteres peculiares de cada espécie, como os aspectos dendrológicos supracitados, de modo a implantar e manter uma arborização com qualidade superior em seus campi universitários onde se aproveite de forma eficiente as características das espécies utilizadas, maximizando e mantendo suas funções ecossistêmicas na arborização do campus além de reduzir custos de manutenção além de evitar conflitos entre o componente vegetal e o espaço físico do campus.

O conhecimento técnico aprofundando das espécies a serem trabalhadas em campi universitários é essencial de modo a evitar o plantio de espécies com caracteres danosos à saúde da comunidade acadêmica como exsudatos ou folhas que podem causar reações alérgicas na pele ou nas vias respiratórias ou a tortuosidade do fuste e a presença de raízes superficiais como as raízes escoras, dilatadas ou com presença de sapopemas, que podem causar transtornos na locomoção quando localizadas em área de circulação de pessoas ou ainda espécies que apresentam odores muito fortes e desagradáveis e que podem se tornar incômodos após exposição prolongada. 


\section{CONCLUSÕES}

Com o levantamento foi observado a grande abundância da família Fabaceae e que apenas 5 famílias (Anacardiaceae, Fabaceae, Burseraceae, Bignoniaceae e Myrtaceae) compõem de forma majoritária a vegetação nas áreas de convívio comum no campus Tapajós. A área apresentou baixa heterogeneidade de espécies uma vez que de 76 espécies encontradas 48 apresentam menos de $1 \%$ de representatividade, o que denota alta concentração de indivíduos em poucas espécies.

A caracterização dendrológica tornou possível o agrupamento dos indivíduos em famílias botânicas de acordo com os caracteres levantados além da observação de características macromorfológicas auxiliando na identificação e reconhecimento das espécies. O conhecimento acerca dos caracteres dendrológicos dos indivíduos do campus Tapajós também é importante no auxílio do manejo desses indivíduos e base para os projetos de alteração do espaço físico da IES de modo que o respeito às características peculiares de cada espécie garante uma arborização de qualidade superior além de reduzir custos na manutenção da vegetação e evitar transtornos futuros gerados pela falta de conhecimento técnico acerca dos indivíduos arbóreos utilizados como danos à saúde ou na locomoção da comunidade acadêmica do campus.

As cinco espécies exóticas encontradas não são consideradas ameaças para a comunidade vegetal nativa do campus Tapajós e não apresentam riscos à saúde da comunidade humana, são frutíferas em maioria e servem de fonte de alimento para a fauna ali situada além de não extrapolarem o valor de $15 \%$ de abundância por espécie. No entanto, é necessário o acompanhamento da propagação da espécie L. leucocephala por apresentar rápido desenvolvimento, já observado no momento de realização deste estudo, podendo chegar a suprimir as espécies autóctones presentes na área de estudo, além da possibilidade de remoção do espécime de $F$. benjamina que por possuir raízes conhecidamente agressivas pode vir a causar danos na estrutura situada a sua proximidade.

Os dados fornecidos pelo presente estudo podem servir como fonte informativa ao manejo da comunidade arbórea situada no campus Tapajós da UFOPA, principalmente em situações de expansão do espaço físico, objetivando preservar a vegetação ali situada, destacando a condição de risco de extinção de espécies encontradas no campus, como por exemplo, a espécie $P$. echinata, uma vez que para realização de obras de expansão torna-se necessário o conhecimento do componente vegetal por meio de inventário contínuo de forma a assegurar o corte de árvores sem efeitos negativos na paisagem do campus Tapajós, ou perda de espécies raras, endêmicas, ou ainda aquelas cujo corte está proibido por lei.

Os resultados obtidos também contribuem para o maior conhecimento do patrimônio vegetal situado no espaço ocupado pela universidade, buscando fomentar o interesse pelo conhecimento, por parte da comunidade que convive rotineiramente com este componente vegetal, de modo a despertar o senso de preservação e manutenção dos serviços ecossistêmicos prestados por essas árvores à comunidade em geral.

\section{REFERÊNCIAS}

APG III. An update of the Angiosperm Phylogeny Group classification for the orders and families of flowering plants:
APG III. Botanical Journal of the Linnean Society, v.161, n.2 p.105-121, 2009. 
BARROS, E. F. S.; GUILHERME, F. A. G.; CARVALHO, R. S... Arborização urbana em quadras de diferentes padrões construtivos na cidade de Jataí. Revista Árvore, Viçosa, v.34, n.2, p.287-295, 2010. DOI: http://dx.doi.org/10.1590/S0100$\underline{67622010000200011}$

BASTOS, F. E. A.; CAMARGO, S. S.; MENEGUZZI, A.; KRETZCHMAR, A. A.; RUFATO, L.. Levantamento florístico e características das espécies em praças públicas em Lages/SC. Revista da Sociedade Brasileira de Arborização Urbana, Piracicaba, v.11, n.1, p.34-42, 2016.

BRIANEZI, D.; JACOVINE, L. A. G.; GONÇALVES, W.; ROCHA, S. J. S.. Avaliação da arborização no campus-sede da Universidade Federal de Viçosa. Revista da Sociedade Brasileira de Arborização Urbana, Piracicaba, v.8, n.4, p.89106, 2013.

COSTA, J. N. M. N.; DURGAN, G.. Leucaena leucocephala (Lam.) de Wit (Fabaceae): invasora ou ruderal?. Revista Árvore, Viçosa, v.34, n.5, p.825-833, 2010. DOI: http://dx.doi.org/10.1590/S0100-67622010000500008

COSTA, C. D. P.; ESTEVAN, D. A.; SILVA, V. M.; GORENSTEIN, R.. Levantamento florístico e mapeamento do arboreto da Universidade Tecnológica Federal do Paraná, Campus Dois Vizinhos. In: CONGRESSO DE CIÊNCIA E TECNOLOGIA DA UNIVERSIDADE TECNLÓGICA FEDERAL DO PARANÁ, 1. Anais. Curitiba: CCTUTFP, 2011.

COSTA, R. S.; OLIVEIRA, I. V. M.; MÔRO, F. V.; MARTINS, A. B. G.. Aspectos morfológicos e influência do tamanho da semente na germinação do jambo-vermelho. Revista Brasileira de Fruticultura, Jaboticabal, v.28, n.1, p.117-120, 2006. DOI: http://dx.doi.org/10.1590/S010029452006000100032

GONÇALVES, E. G.; LORENZI, H.. Morfologia Vegetal: Organografia e dicionário ilustrado de morfologia das plantas vasculares. São Paulo: Instituto Plantarum de Estudos da Flora, 2007.

INMET. Instituto Nacional de Meteorologia. Dados da Rede do INMET. 2018.

KERN, D. I.; SCHMITZ, J. A. K.. Arborização de vinte quarteirões amostrados na região central de Santa Cruz do Sul- RS. Revista da Sociedade Brasileira de Arborização Urbana, Piracicaba, v.8, n.3, p.79-95, 2013.

LEITE, E. C.; FARIA, L. C.; CAPELO, F. F. M.; TONELLO, K. C.; CASTELLO, A. C. D.. Composição florística da arborização urbana de Sorocaba/SP, Brasil. Revista da Sociedade Brasileira de Arborização Urbana, Piracicaba, v.9, n.1, p.133150, 2014.

LORENZI, H.. Árvores Brasileiras: manual de identificação e cultivo de plantas arbóreas nativas do Brasil. 2 ed. Nova Odessa: Plantarum, 1998.

MARCHIORI, J. N. C.. Dendrologia. 3 ed. Santa Maria: UFSM, 2013.

MELO, E. F. R. Q.; SEVERO, B. M.. Vegetação arbórea do campus da Universidade de Passo Fundo. Revista da Sociedade Brasileira de Arborização Urbana, Piracicaba, v.9, n.2, p.77-86, 2017.
MILLER, D. Z.. Caracterização dendrológica da família Fabaceae em um remanescente de floresta ombrófila mista, Curitiba, Pr. Curitiba, 2015. Monografia (Bacharelado em Engenharia Florestal) - Universidade Federal do Paraná, Curitiba, 2015.

MIRANDA, T. O.; CARVALHO, S. M.. Levantamento quantitativo e qualitativo de indivíduos arbóreos presentes nas vias do bairro da ronda em Ponta Grossa - PR. Revista da Sociedade Brasileira de Arborização Urbana, Piracicaba, v.4, n.3, p.143-157, 2009.

OBERMÜLLER, F. A.; DALY, D. C.; OLIVEIRA, E. C.; SOUSA, H. F. T. P.; OLIVEIRA, H. M.; SOUZA, L. S.; SILVEIRA, M.. Guia ilustrado e manual de arquitetura foliar para espécies madeireiras na Amazônia Ocidental. Rio Branco: UFAC, 2011.

OLIVEIRA, F. A. C.; SILVA, L. M.; HASSE, I.; CADORIN, D. A.; OLIVEIRA, K. A.. Inventário da arborização do Campus Pato Branco da Universidade Tecnológica Federal do Paraná UTFPR. Revista da Sociedade Brasileira de Arborização Urbana, Piracicaba, v.4, n.1, p.93-106, 2009.

OLIVEIRA, K. M. M.; SILVA, F. R. S.; ALVES, P. H. C. S. A.; SILVA, M. A.; CARAVALHO, R. A.; ARAÚJO, L. C. P.; FREITAS, A. D. D.. Levantamento dendrológico de um fragmento de floresta ombrófila aberta no município de Altamira-PA. In: SIMPÓSIO DE CIÊNCIAS AGRÁRIAS DA AMAZÔNIA, 2. Anais. Santarém: UFOPA, 2015.

PAIVA, A. V.. Aspectos da arborização urbana do centro de Cosmópolis/SP. Revista da Sociedade Brasileira de Arborização Urbana, Piracicaba, v.4, n.4, p.17-31, 2009.

PATRÍCIO, P. P. M.. Florística e diagnóstico da arborização da Universidade Federal de Mato Grosso.

Dissertação(Mestrado em Ciências Florestais e Ambientais) Universidade Federal de Mato Grosso, Cuiabá, 2017.

RIBEIRO, J. E. L. S.; HOPKINS, M. J. G.; VICENTINI, A.; SOTHERS, C. A.; COSTA, M. A. S.; BRITO, J. M.; SOUZA, M. A. D. L. H.; LOHMANN, L. G.; ASSUNÇÃO, P. A.; PEREIRA, E. C.; SILVA, C. F.; MESQUITA, M. R.; PROCÓPIO, L. C.. Flora da Reserva Ducke. Guia de identificação das plantas vasculares de uma floresta de terra firme na Amazônia Central. Manaus: INPA-DFID, 1999.

RODRIGUES, B. P.; MAURI, R. M.; SILVA, A. G.; OLIVEIRA, J. T. S.. Caracterização dendrológica e anatômica de Cariniana legalis (Mart.) Kuntze (Lecythidaceae). In: ENCONTRO LATINO AMERICANO DE INICIAÇÃO CIENTÍFICA E ENCONTRO LATINO AMERICANO DE PÓS-GRADUAÇÃO, 9. Anais. João Pessoa: EPG, 2011.

SANTOS, E.; MARANGON, L. C.; RAMALHO, R. S.. Levantamento dendrológico da bacia do rio São Bartolomeu, Viçosa - Minas Gerais. Revista Ceres, v.45, n.260, 1998.

SANTOS, L. R.; SANTOS, E. A.; PINHEIRO, R. M.; FERREIRA, E. J. L.. Diagnóstico da arborização do parque urbano tucumã em Rio Branco/AC. Revista da Sociedade Brasileira de Arborização Urbana, Piracicaba, v.12, n.2, p.103-116, 2017. 
SILVA, R. C. V.; SILVA, A. S. L.; FERNANDES, M. M.; MARGALHO, L. F.. Noções morfológicas e taxonômicas para identificação botânica. Brasília: Embrapa, 2014.

SILVA, L.; HASSE, I. M.; MOCCELIN, R.; ZBORALSKI, A. R. Arborização de vias públicas e a utilização de espécies exóticas: O caso do bairro centro de Pato Branco/Paraná. Scientia Agraria, v.8, n.1, p.47-53, 2007.

DOI: http://dx.doi.org/10.5380/rsa.v8i1.8341

SILVA, S.. Árvores da Amazônia. São Paulo: Empresa das artes, 2006.
SOUZA, F. P. A.; PAIVA, A. M. S.. Levantamento arbóreo do Instituto Federal de Educação, Ciência e Tecnologia de São Paulo (IFSP), Campus São Paulo. Revista da Sociedade Brasileira de Arborização Urbana, Piracicaba, v.9, n.2, p.7786,2014

TEIXEIRA, I. F.; FIGUEIREIDO, F. M.; TABORDA, I. G. R.; SOARES, L. M.. Análise fitossociológica da Praça Camilo Mércio no entro histórico de São Gabriel, RS. Revista da Sociedade Brasileira de Arborização Urbana, Piracicaba, v.11, n.1, p.1-13, 2016.

A CBPC - Companhia Brasileira de Produção Científica (CNPJ: 11.221.422/0001-03) detém os direitos materiais desta publicação. Os direitos referem-se à publicação do trabalho em qualquer parte do mundo, incluindo os direitos às renovações, expansões e disseminações da contribuição, bem como outros direitos subsidiários. Todos os trabalhos publicados eletronicamente poderão posteriormente ser publicados em coletâneas impressas sob coordenação da Sustenere Publishing, da Companhia Brasileira de Produção Científica e seus parceiros autorizados. Os (as) autores (as) preservam os direitos autorais, mas não têm permissão para a publicação da contribuição em outro meio, impresso ou digital, em português ou em tradução. 